Article

\title{
Socioeconomic Status Impact Hypertensive Risk and Treatment among Older Adults in China
}

\author{
Cuicui Xia ${ }^{*}$ and Jianxin $\mathrm{Li}^{2}$ \\ ${ }^{1}$ Institute of Population and Labor Economics, Chinese Academy of Social Sciences, Dongcheng District, Beijing, China \\ 2 Peking University, Haidian District, Beijing, China
}

Received January 26, 2019; Accepted: March 25, 2019

\begin{abstract}
Background: Hypertension has become one of the significant health problems among the elderly. The disparities in the prevalence, awareness, and treatment of hypertension have been associated with socioeconomic status but lack of consistency especially in developing countries where is undergoing epidemiological transition.

Methods: Data used in this study was drawn from the 2013 wave of the China Health and Retirement Longitudinal Study (CHARLS), which was designed with a multi-stage clustering population-based sampling. The dependent variables were hypertension as well as self-awareness and treatment of hypertension, both of which were measured as binary outcomes. The independent variables included the community and individual socioeconomic conditions mainly measured by education, income and occupations. A hierarchical logistic regression model was used for statistical analysis to considering the clustering at community level.

Results: Individuals aged 45 years or older living in urban areas (Beta $=0.144 ; \mathrm{p}<0.1$ ) and communities with higher mandarin fluency score (Beta=0.043; $<<0.05$ ) were positively associated with the risk of hypertension. Compared with agricultural workers, the retired (Beta $=0.425 ; \mathrm{p}<0.001$ ), people working for government or institutions (Beta $=0.519$; $\mathrm{p}<0.001$ ), working with a large company (Beta $=0.362 ; \mathrm{p}<0.05)$, farmer or working with a small private firm (Beta $=0.302$; $\mathrm{p}<0.05$ ) were more likely to be hypertensive. We also found that urban living (Beta=0.194; $\mathrm{p}<0.1$ ) and communities with a higher mandarin fluency score $(B e t a=0.061 ; \mathrm{p}<0.05)$ were associated with a higher awareness of hypertension. There was a noted regional variation in both the awareness and treatment of hypertension; people living in the western China were less likely to be aware of (Beta=-0.186; $\mathrm{p}<0.1$ ) and to manage their hypertension (Beta=-0.297; $\mathrm{p}<0.05$ ) compared to those in the more developed eastern China. The inequality in treatment was also observed among occupations; the retired $($ Beta=0.785; $\mathrm{p}<0.001)$, individuals working for government or institutions (Beta=0.437; $\mathrm{p}<0.1$ ) or for a private firm (Beta $=0.395 ; \mathrm{p}<0.1$ ) were more likely to receive treatment for hypertension.

Conclusion: Occupation, urban dwelling, and living in the more developed eastern China were associated with more likelihood of developing hypertension and being aware of and treated for hypertension. However, income and levels of education, two classical measures of socioeconomic status, were not associated with either of the three outcomeshypertensive risk, awareness and treatment in China.
\end{abstract}

\section{KEYWORDS}

Hypertension, blood pressure management, socioeconomic status

\section{INTRODUCTION}

Hypertension is defined as blood pressure elevated to an unhealthy level. It is a measure of the force exerted by the blood against the wall of the blood vessels and depends on the strength of heart pumping and the resistance of the blood vessels. Normally, the blood pressure is 120 (systolic) and 80 (diastolic) $\mathrm{mm}$ of mercury ( $\mathrm{mmHg}$ ) but can be acutely elevated by stress or physical activity; and blood pressure is increased as people aging. Hypertension is blood pressure higher than 130/80 (1) if unmanaged can lead to severe complications and increase the risk of heart disease, stroke, and mortality.

Hypertension has become one of the significant threats to health in the less developed country such as China where there has been a rapid social and economic, demographic and epidemiological transition. There are a large number of individuals with hypertension, as well as a high prevalence but low rate of treatment in China. Nationally, it was estimated that about 330 million people suffered from hypertension in 2012, accounting for one-third of global

\footnotetext{
* Correspondence: Cuicui Xia, Email: cuicuixia0710@126.com
} 
hypertension patients. Because of population aging and epidemiological transitions, hypertension became a major health problem that the elderly face. In 2002, 50\% of the elderly aged at 60 years or above suffered from hypertension in China, but only $32.2 \%$ of individuals had medical treatment. In 2012, the prevalence of hyper-tension among the elderly in China increased to $60 \%$ and the treatment rate remained low as only $41 \%$ of patients received the treatment they needed; most of the patients did not get any effective treatment at all (2).

There is long-standing literature showing that generally people living in a relatively better community environment and with a higher individual socioeconomic status (SES) tend to be healthier. Socioeconomic status may determine the ability of an individual to acquire resources and live with a certain healthier lifestyle (3); whereas individuals with low socioeconomic status are more likely to smoke and drink excessively, have more stressful life events and high-calorie diet, which lead to a higher prevalence of diseases and less healthy conditions $(4,5)$. The community socioeconomic conditions also contribute to health and prevalence of illness. In the more developed regions, the standard of living and medical services are better and more accessible, which may result in a positive influence on health (6).

However, the relationship between individual socioeconomic status and prevalence of hypertension has been reported in multiple studies but lack of consistency (7). In the developing countries undergoing epidemiological transition, groups with a higher socioeconomic status may first experience the epidemiological transition that the pattern of dominant diseases is transited from communicable diseases to chronic diseases; therefore, they may first have increased the likelihood of being hypertensive. In contrast, in the more developed countries, there is a negative correlation between socioeconomic status and the risk of hyper-tension. A case-control study in Singapore indicates that the prevalence of hypertension was relatively low in the wealthy communities and the treatment rate was relatively high (8). A US-based study also shows that the prevalence of hypertension was low in communities with relatively higher average income per capita; and social and environ-mental exposure explained a substantial proportion of the racial disparity in hypertension (9). Data from Europe also indicates that low socioeconomic status was a significant risk factor for hypertension in adolescents (10).

Moreover, the relationship of socioeconomic status with hypertension is complicated in some other countries. In a study of women (15-65 years of age) in low-income regions of rural Mexico in 2003, groups with a higher level of house-hold income and assets were more likely to suffer from hypertension(11). This challenges the current popular hypothesis of socioeconomic status and health. In South Africa, the males with high levels of education and income had a higher prevalence of hypertension, but the result was opposite in the females (12). However, the socioeconomic conditions such as education, income and wealth had no significant effect on the risk of hypertension; and they also evidently influenced the treatment of hyper-

https://www.gcatresearch.com tension (13). Recent research using panel data shows that the association between socioeconomic status and hypertension had started changing in China. In the males, people with a higher level of socioeconomic status were more likely to have hypertension from 1991 to 2006; whereas people with a lower level of socioeconomic status were more likely to have hypertension from 2006 to 2009. In both periods together from 1993 to 2009, a lower level of socioeconomic status was associated with the risk of hypertension in the females (13).

This inconsistency may reflect the dynamics and imbalanced change in social, economic transition, but may also be likely due to the lack of nationally representative sample. Identifying the groups that are most vulnerable to be hypertensive or less likely aware of and to control their blood pressure, may have an important implication for public health. Previous studies have mainly used the income and levels of educational attainment as the measures of socioeconomic status, but rarely considering the occupational influence and community socioeconomic conditions. With a large national representative sample, this study examined the relationship between hypertension and socioeconomic status, which was measured by not only the household income, personal education, and occupation, but also the community socioeconomic status and urban dwelling. We also examined how the socioeconomic status affects the self-awareness and treatment of hypertension, in which poor socioeconomic status has been associated with uncontrolled hypertension (14). Findings from this study will help to target vulnerable population for effective prevention.

\section{METHODS}

\section{Dataset}

Data used in our research was drawn from the 2013 national representative baseline survey of the China Health and Retirement Longitudinal Study (CHARLS). The original study design has been described elsewhere (15). In brief, the original survey was a national representative and samples were from 450 villages and communities in 150 counties across China, with a total of 18,604 samples aged 45 years old or above. The CHARLS survey comprised a community questionnaire that is used to collect an extensive set of information on the community income per capita and social development, and an individual questionnaire that was used to collect a detailed information on individual's education, occupation, household per capita income, behaviors and health conditions. Diastolic pressure and systolic pressure were measured by trained nurses and were recorded three times at the time when the survey was conducted. Respondents were also interviewed about their awareness and treatment conditions of hypertension.

\section{Measurement of variables}

Dependent Variables: Both self-reported and actual hypertension was collected as outcome variables of this study. The self-reported hypertension was defined as 1 if respondents in this survey answered "Yes" to the question "Have you been diagnosed with hypertension by a doctor?" which 
means they had been diagnosed before, which may not reflect the current conditions of hypertension. The diagnosed hypertension was defined by the actual blood pressure of the respondents, which was the average of blood pressure recorded three times by trained nurses in this survey. A respondent was considered suffering diagnosed hypertension if any one of the following conditions met 1) the mean systolic pressure of three repeated measures was $140 \mathrm{mmHg}$ or above, 2) the mean diastolic pressure was $90 \mathrm{mmHg}$ or above, and 3) the respondent was taking medicines to control blood pressure. In addition, the awareness of hypertension is defined as 1 if respondents actually suffered from hypertension and had been diagnosed with hypertension by a physician; and the treatment condition of hypertension is measured by whether the respondent is taking medicines or anti-hypertensive treatment to control blood pressure. The awareness of hypertension and the treatment condition of hypertension were only measured for the elderly who were diagnosed with hypertension in this paper.

Independent Variable: The main explanatory variables included community and individual socioeconomic status (SES) variables. Four indicators were used to measure community socioeconomic conditions: type of community (rural or urban), community income per capita, the level of mandarin fluency and the geographic regions (East, Central, and West) of the community. Three indicators were used to measure individual socioeconomic status: level of individual educational attainment, family income per capita, and occupations.

Control variables: We also included some variables such as age, gender, marital status, smoking history, social participation, diet control, body mass index (BMI), having medical insurance and taking a physical examination, to control for potential confounding.

\section{Statistical analysis}

Because the samples were from a cluster sampling, a random-effect (hierarchical) logistic regression model was used for statistical analysis. The individual variable was considered as level one, the community was considered as level two. The model is written briefly as follow:

$\operatorname{logit}(\mathrm{p})=\gamma_{00}+\gamma_{01} \mathrm{w}_{\mathrm{j}}+\gamma_{10} \mathrm{X}_{\mathrm{ij}}+\delta_{0 \mathrm{j}}$

Where $W_{j}$ is the community socioeconomic context and $\gamma_{01}$ is its coefficient; $X_{i j}$ represents the socioeconomic conditions at individual level and $\gamma_{10}$ is its coefficient. In this model, a random effect varies with the communities but the slopes are the same; $\delta_{0 j}$ is the random-effect at a community level. $\mathrm{P}$ represents the odds of being hypertensive. The data was analyzed using the software Stata Release 14.0.

\section{RESULTS}

Table 1 presents the coding and descriptive statistics of the variables. In the 2013 wave of CHARLS survey. The total number of samples were18, 604; however, the actual response rate was different for individual outcomes. Of the total sample, 14,298 (76.85\%) participants of middle-aged and the elderly (age > $=45$ years,) had complete information on clinical diagnosis; and $47.76 \%(6,829$ of 14,298$)$ were suffering from hyper-tension, which is confirmed by measuring the blood pressure in the survey. There was a high rate of response $(94.81 \%, 17,639 / 18604)$ in self-reported hypertension; of which only $26.42 \%(4,660$ of 17,639$)$ respondents had self-reported hypertension, indicating that more than $30 \%(2,169 / 6,829)$ of hypertensive people failed to report that they had hypertension.

In addition, we noted that the rates of self-awareness and receiving treatment were low. Of the 6829 respondents who were actually suffering from hypertension, only $61.29 \%$ (4,022 /6,562; 267 missing) diagnosed with hypertension and responded to the survey were aware of their hypertension. About $60 \%(4,047 / 6,822,7$ missing $)$ respondents who were diagnosed as hypertension were receiving treatment at the time when the survey was conducted.

Table 2 presents the association of socioeconomic status and other factors with the diagnosed and self-reported hypertension. Communities with a higher level of mandarin fluency score (Beta $=0.043 ; \mathrm{p}<0.05)$ are more likely to be hypertensive (Model 1). Compared with agricultural workers, the retired individuals (Beta $=0.425, \mathrm{p}<0.001$ ), working for government or institutions (Beta=0.519; Odd Ratio, OR=1.68; $\mathrm{p}<0.001$ ), working for a company (Beta $=0.362 ; \mathrm{p}<0.05)$, working for farmer or a private firm (Beta $=0.302 ; \mathrm{p}<0.05)$ were more likely to be diagnosed with hypertension. Individuals who living in the urban areas (Beta $=0.144 ; \mathrm{p}<0.1$ ) had a trend to be hypertensive. However, community income per capita, levels of educational attainment, and household income per capita were not significantly associated with hypertension. The estimates of socioeconomic status on the self-reported hypertension were similar to that was for the diagnosed hypertension (Model 3).

When controlling for factors such as drinking alcohol, diet behavior, and access to health care resource, urban living and high level of mandarin fluency score that was associated with diagnosed hypertension and self-reported hypertension became no longer significant (Model 2 and Model 4). We noted that BMI (Beta=0.144; $<<0.001$ ) and having alcohol-drinking history (Beta=0.161; $\mathrm{p}<0.01$ ) were positively related to being hypertensive. When BMI, behavior, and access to health care were controlled in the analysis, the association between urban dwelling and mandarin language fluency with the diagnosed hypertension and self-reported hypertension were no longer significant, suggesting that those variables mediated the association with urban dwelling and mandarin language fluency. In addition, we noted that there were significant random-effects $(\mathrm{RE})$ in model $1(\mathrm{RE}=0.239 ; \mathrm{P}<0.001)$ and model 2 ( $\mathrm{RE}=0.203$; $\mathrm{P}<0.001)$ for the diagnosed hypertension; and significant random-effects were also noted in model 3 (RE= 0.251; $\mathrm{P}<0.001$ ) and model $4(\mathrm{RE}=0.124$; $\mathrm{P}<0.001$ ) for association with self-reported hypertension. These suggest that marked unobserved heterogeneity was at community level or some important factors that may be associated with hyper-tension were not observed and included in the analysis. 
Table 1. Coding and descriptive statistics of variables $(n=18,604)$

\begin{tabular}{|c|c|c|c|c|c|c|}
\hline Variable & Coding & Mea & Medi & SD & $\mathrm{N}$ & $\%$ \\
\hline \multicolumn{7}{|l|}{ Dependent variables } \\
\hline \multirow[t]{2}{*}{ Diagnosed hypertension } & $1=$ Yes & & & & 6,829 & 47.76 \\
\hline & $0=\mathrm{No}$ & & & & 7,469 & 52.24 \\
\hline \multirow[t]{2}{*}{ Self-reported hypertension } & $1=$ Yes & & & & 4,660 & 26.42 \\
\hline & $0=\mathrm{No}$ & & & & 12.979 & 73.58 \\
\hline \multirow{3}{*}{ Awareness of hypertension } & $1=$ Yes & & & & 4,022 & 61.29 \\
\hline & $0=$ No & & & & 2,540 & 38.71 \\
\hline & NA & & & & 267 & \\
\hline \multirow[t]{2}{*}{ Treating hypertension } & $1=$ Yes & & & & 4,047 & 59.32 \\
\hline & $\begin{array}{l}0=\text { No } \\
\text { Missing }\end{array}$ & & & & $\begin{array}{r}2.775 \\
7\end{array}$ & 40.68 \\
\hline \multicolumn{7}{|l|}{ Individual socioeconomic conditions } \\
\hline \multirow[t]{2}{*}{ Education } & $0=$ Illiterate & & & & 8,099 & 43.57 \\
\hline & $\begin{array}{l}1=\text { Elementary school } \\
2=\text { Middle school and above }\end{array}$ & & & & $\begin{array}{l}4,148 \\
6,340\end{array}$ & $\begin{array}{l}22.32 \\
34.11\end{array}$ \\
\hline \multirow[t]{7}{*}{ Occupation } & $0=$ Agricultural worker & & & & 9.431 & 51.48 \\
\hline & $1=$ Retired & & & & 5,885 & 32.13 \\
\hline & $2=$ Self-employed & & & & 833 & 4.55 \\
\hline & $3=$ Government or Institution worker & & & & 405 & 2.21 \\
\hline & 4=Company employee & & & & 555 & 3.03 \\
\hline & $5=$ Farmer or private firm & & & & 682 & 3.72 \\
\hline & $6=0$ thers & & & & 530 & 2.89 \\
\hline Household income per capita (ln) & & 8.71 & 8.95 & 1.52 & 17,543 & \\
\hline \multicolumn{7}{|l|}{ Community socioeconomic conditions } \\
\hline \multirow[t]{2}{*}{ Community type } & $1=$ Urban & & & & 4,577 & 24.64 \\
\hline & $0=$ Rural & & & & 14,002 & 75.36 \\
\hline Community income per capita(ln) & & 8.00 & 8.07 & 1.21 & 17,603 & \\
\hline Degree of mandarin fluency & & 3.86 & 4.00 & 1.83 & 18,555 & \\
\hline \multirow[t]{2}{*}{ Region } & $\begin{array}{l}0=\text { Eastern } \\
1=\text { Central }\end{array}$ & & & & $\begin{array}{l}7.796 \\
6,085\end{array}$ & $\begin{array}{l}41.88 \\
32.69\end{array}$ \\
\hline & $2=$ Western & & & & 4,733 & 25.43 \\
\hline \multicolumn{2}{|l|}{$\begin{array}{l}\text { Controlled variables } \\
\text { Age }\end{array}$} & 60.2 & 59.00 & 10.0 & 18,205 & \\
\hline Gender & $1=$ Female & & & & 8,861 & 47.66 \\
\hline Marital status & $\begin{array}{l}0=\text { Male } \\
1=\text { Currentlv married } \\
0=0 \text { therwise }\end{array}$ & & & & $\begin{array}{r}9733 \\
3.500 \\
15,085\end{array}$ & $\begin{array}{l}52.34 \\
18.83 \\
81.17\end{array}$ \\
\hline \multirow[t]{2}{*}{ Ever drinking alcohol } & $1=$ Yes & & & & 6,411 & 34.93 \\
\hline & $\begin{array}{l}0=\text { No } \\
1=\text { Yes }\end{array}$ & & & & $\begin{array}{l}11.945 \\
11.405\end{array}$ & $\begin{array}{l}65.07 \\
61.80\end{array}$ \\
\hline Participating in social activities & $0=\mathrm{No}$ & & & & 7,050 & 38.20 \\
\hline \multirow[t]{2}{*}{ Controlling diet } & $1=$ Yes & & & & 14,149 & 84.08 \\
\hline & $0=$ No & & & & 2,680 & 15.92 \\
\hline \multirow{3}{*}{$\begin{array}{l}\text { Body Mass Index } \\
\text { Taking physical examination }\end{array}$} & & 23.8 & 23.59 & 3.86 & 12,959 & \\
\hline & $1=$ Yes & & & & 7,543 & 42.12 \\
\hline & $0=$ No & & & & 10.364 & 57.88 \\
\hline \multirow{2}{*}{ Having medical insurance } & $1=$ Yes & & & & 17,672 & 95.87 \\
\hline & $0=\mathrm{No}$ & & & & 761 & 4.13 \\
\hline
\end{tabular}

Note: actual sample size for each item could be varied due to the missing value.

Table 3 shows the associated factors for the awareness and treatment of hypertension. Communities with higher mandarin fluency score (Beta $=0.061 ; p<0.05$ ) and urban living (Beta=0.194; $\mathrm{p}<0.1$ ) were with a relative higher awareness (Model 1). Inequality in the proportion of awareness was found different between occupations, with retired people (Beta=0.785; $\mathrm{p}<0.001$ ), government employee (Beta= 0.437; $\mathrm{p}<0.1)$, working for a firm (Beta $=0.395$; $<<0.1$ ) were more likely to be aware of hypertension compared with agricultural workers. People living in the less developed Western China (Beta=-0.186; $\mathrm{p}<0.1$ ) were less likely aware of their hypertension. When the access to health care resource such as having medical insurance and taking a physical examination were controlled (Model 2), the association of urban living with the awareness of hyper- tension was no longer significant (Beta=0.177; $\mathrm{t}=1.51$ ). This may indicate that the inequalities in the access to health services between rural and urban residents were responsible for the disparity of the awareness. Community income per capita, levels of educational attainment and household income per capita had no significant association with the awareness of hypertension.

The treatment varied significantly with the region and occupation among the middle-aged and the elderly who were diagnosed with hypertension. People living in the western China were less likely to treat their hypertension (Beta $=-0.297 ; \mathrm{p}<0.05)$. The retired (Beta $=0.592 ; \mathrm{p}<0.001$ ) and people working for the business company (Beta=1.112; $\mathrm{p}<0.05$ ) were more likely to treat their hypertension than 
agricultural workers were (Model 3). Community income per capita, level of educational attainment and household income per capita had little effect. We noted that there were significant random-effects in model 1 ( $R E=0.361$; $\mathrm{p}<0.05)$ and in model $2(\mathrm{RE}=0.37 ; \mathrm{p}<0.001)$ for the aware- ness of hypertension, and in model $3(\mathrm{RE}=0.248$; $\mathrm{p}<0.05)$ and in model 4 (RE=0.239; $\mathrm{p}<0.05)$ of hypertension treatment, suggesting that there were unobserved heterogeneity at community or factors that may be associated with aware-ness and treatment of hypertension.

Table 2 Multiple logistic regression estimates of socioeconomic conditions on the incidence of hypertension ( $\mathrm{n}=12,131)$

\begin{tabular}{|c|c|c|c|c|c|c|c|c|c|c|c|c|}
\hline & \multicolumn{5}{|c|}{ Diagnosed hvpertension } & \multicolumn{7}{|c|}{ Self-reported hvpertension } \\
\hline & \multicolumn{2}{|c|}{ Model 1} & \multirow[b]{2}{*}{ Sig } & \multicolumn{2}{|c|}{ Model 2} & \multirow[b]{2}{*}{ Sig } & \multicolumn{2}{|c|}{ Model 3} & \multirow[b]{2}{*}{ sig } & \multicolumn{3}{|c|}{ Model 4} \\
\hline & Beta & SE & & Beta & SE & & Beta & SE & & Beta & SE & Sig \\
\hline Intercept & -2.78 & 0.194 & $* * *$ & -7.011 & 0.375 & $* * *$ & -3.132 & 0.307 & *** & -7.971 & 0.402 & $* * *$ \\
\hline Community & & & & & & & & & & & & \\
\hline Urban living & 0.144 & 0.087 & + & -0.034 & 0.087 & & 0.184 & 0.086 & $*$ & -0.043 & 0.084 & \\
\hline Community income per & & & & & & & & & & & & \\
\hline capita $(\ln )$ & -0.04 & 0.027 & & -0.027 & 0.027 & & -0.044 & 0.028 & & -0.027 & 0.026 & \\
\hline Mandarin fluency score & 0.043 & 0.019 & * & 0.016 & 0.019 & & 0.058 & 0.020 & $* *$ & 0.036 & 0.018 & + \\
\hline Education & & & & & & & & & & & & \\
\hline Illiterate & & & & & & & & & & & & \\
\hline Elementary school & 0.001 & 0.052 & & -0.026 & 0.057 & & 0.033 & 0.056 & & -0.001 & 0.063 & \\
\hline Middle school and above & 0.008 & 0.055 & & -0.022 & 0.06 & & -0.043 & 0.059 & & -0.119 & 0.067 & + \\
\hline Occupation & & & & & & & & & & & & \\
\hline Agricultural worker & & & & & & & & & & & & \\
\hline Retired & 0.425 & 0.089 & $* * *$ & 0.230 & 0.057 & $* * *$ & 0.587 & 0.054 & $* * *$ & 0.29 & 0.062 & $* * *$ \\
\hline Self-employed & 0.166 & 0.102 & & -0.086 & 0.114 & & 0.282 & 0.113 & $*$ & 0.02 & 0.13 & \\
\hline Government worker & 0.519 & 0.155 & $* * *$ & 0.236 & 0.174 & & 0.551 & 0.167 & $* * *$ & 0.151 & 0.196 & \\
\hline Company employee & 0.362 & 0.142 & $*$ & 0.095 & 0.167 & & 0.442 & 0.156 & $*$ & 0.226 & 0.191 & \\
\hline Farmer or individual firm & 0.302 & 0.122 & * & 0.098 & 0.142 & & 0.286 & 0.137 & $*$ & 0.066 & 0.168 & \\
\hline Others & 0.452 & 0.122 & $* * *$ & 0.282 & 0.138 & $*$ & 0.563 & 0.125 & $* * *$ & 0.423 & 0.144 & $* *$ \\
\hline $\begin{array}{l}\text { Household income per } \\
\text { capita }(\ln )\end{array}$ & -0.02 & 0.014 & & -0.020 & 0.017 & & 0.019 & 0.015 & & -0.01 & 0.019 & \\
\hline Controlling variables & & & & & & & & & & & & \\
\hline Ever drinking alcohol & & & & 0.161 & 0.053 & $* *$ & & & & 0.112 & 0.059 & + \\
\hline Participating in social & & & & & & & & & & & & \\
\hline activities & & & & -0.030 & 0.031 & & & & & -0.042 & 0.057 & \\
\hline Controlling diet & & & & -0.073 & 0.091 & & & & & 0.016 & 0.071 & \\
\hline Body Mass Index & & & & 0.144 & 0.006 & $* * *$ & & & & 0.155 & 0.007 & $* * *$ \\
\hline Having medical insurance & & & & -0.083 & 0.117 & & & & & 0.286 & 0.144 & $*$ \\
\hline Physical examination & & & & 0.095 & 0.046 & $*$ & & & & 0.441 & 0.050 & $*$ \\
\hline Random intercept & 0.239 & 0.029 & $* * *$ & 0.203 & 0.03 & $* * *$ & 0.251 & 0.033 & $* * *$ & 0.124 & 0.026 & $* * *$ \\
\hline
\end{tabular}

Note: $1 .{ }^{* * *} \mathrm{P}<0.001,{ }^{* *} \mathrm{P}<0.01,{ }^{*} \mathrm{P}<0.05,+\mathrm{P}<0.1$;

2. Coefficients are adjusted by age; gender and marital status in all models.

\section{DISCUSSIONS}

Through the analysis of a large national representative sample, we found that socioeconomic conditions were associated with the risk of hypertension. In China, the middle-aged and elderly living in urban, mandarin language fluency, and working in non-agricultural sectors were more likely to be hypertensive. These associations were to a certain degree mediated by BMI, drinking history and access to health services; and controlling for BMI and drinking history, the associations were no longer significant. We did not find a significant association of personal education and household income with the risk of hypertension.

Our findings confirmed that socioeconomic status with the risk of hypertension, but showed some different from previous literature or studies conducted in other countries. We noted that household income per capita, individual's education, and community income per capita, two of which are well known for measuring individual's SES, are not significantly associated with risk of hypertension. However, these factors have been associated with the risk of hypertension in other countries including both developing and less developed countries $(7,14,16)$. Instead, occupation is strongly associated with the risk of hyper-tension in China, which has been reported in the previous study(17). It is interesting to note that government and institutional workers, which are mostly state-own, have the highest risk of hypertension compared to the agricultural workers and other occupations in China. These probably suggest that lack of activity may play a role in the risk of hypertension because they are mostly engaged with work in the office but fewer outside activities. In the meantime, people who live in urban areas may have first experienced the epidemiological transition that is mostly induced by socioeconomic development and they may be likely hypertensive. In addition, a study in Japan did not find a clear association of SES with hypertension (18). Moreover, the association between individual socioeconomic status and the risk of hypertension may be affected by some unobserved hetero- 
geneity of the elderly who were from different birth cohorts and suffered varied impacts from socioeconomic factors, which can be further explored by using multiwaves data.

Table 3 Multiple logistic regression estimates of socioeconomic conditions on awareness and treatment of hypertension

\begin{tabular}{|c|c|c|c|c|c|c|c|c|c|c|c|c|}
\hline & \multicolumn{5}{|c|}{ Hypertension awareness } & \multicolumn{6}{|c|}{ Hypertension treatment } & \multirow[b]{3}{*}{ Sig } \\
\hline & \multicolumn{2}{|c|}{ Model 1} & \multirow[b]{2}{*}{ Sig } & \multicolumn{2}{|c|}{ Model 2} & \multirow[b]{2}{*}{ Sig } & \multicolumn{2}{|c|}{ Model 3} & \multirow[b]{2}{*}{ Sig } & \multicolumn{2}{|c|}{ Model 4} & \\
\hline & Beta & SE & & Beta & SE & & Beta & SE & & Beta & SE & \\
\hline $\begin{array}{l}\text { Intercept } \\
\text { Community }\end{array}$ & -0.272 & 0.429 & & -0.369 & 0.462 & & 1.612 & 0.711 & $*$ & 1.533 & 0.782 & $*$ \\
\hline Urban & 0.194 & 0.115 & + & 0.177 & 0.117 & & 0.150 & 0.174 & & 0.089 & 0.175 & \\
\hline $\begin{array}{l}\text { Community income } \\
\text { per capita }(\ln )\end{array}$ & -0.039 & 0.037 & & -0.048 & 0.038 & & 0.018 & 0.052 & & 0.023 & 0.052 & \\
\hline $\begin{array}{l}\text { Mandarin fluency } \\
\text { Region } \\
\text { Eastern (ref) }\end{array}$ & 0.061 & 0.026 & $*$ & 0.065 & 0.026 & $*$ & 0.028 & 0.036 & & 0.026 & 0.037 & \\
\hline Central & 0.039 & 0.102 & & 0.076 & 0.104 & & -0.001 & 0.148 & & 0.017 & 0.15 & \\
\hline $\begin{array}{l}\text { Western } \\
\text { Education } \\
\text { Illiterate (ref) }\end{array}$ & -0.186 & 0.109 & + & -0.223 & 0.112 & $* *$ & -0.297 & 0.151 & $*$ & -0.312 & 0.155 & $*$ \\
\hline Elementary school & 0.044 & 0.079 & & 0.034 & 0.08 & & 0.039 & 0.145 & & 0.064 & 0.148 & \\
\hline $\begin{array}{l}\text { Mid school above } \\
\text { Occupation } \\
\text { Agricultural worker }\end{array}$ & -0.056 & 0.083 & & -0.115 & 0.085 & & -0.047 & 0.151 & & -0.08 & 0.153 & \\
\hline Retired & 0.785 & 0.074 & $* * *$ & 0.555 & 0.076 & $* *$ & 0.592 & 0.141 & $* * *$ & 0.643 & 0.143 & $* *$ \\
\hline Self-employed & 0.173 & 0.163 & & 0.22 & 0.166 & & 0.358 & 0.302 & & 0.428 & 0.311 & \\
\hline Government employee & 0.437 & 0.239 & + & 0.317 & 0.246 & & 0.131 & 0.382 & & 0.068 & 0.384 & \\
\hline Company worker & 0.395 & 0.235 & + & 0.423 & 0.245 & + & 1.112 & 0.541 & $*$ & 1.158 & 0.544 & $*$ \\
\hline Farmer or firm & 0.286 & 0.194 & & 0.135 & 0.2 & & 0.175 & 0.34 & & 0.106 & 0.344 & \\
\hline Others & 0.654 & 0.178 & $* * *$ & 0.673 & 0.181 & $* * *$ & 0.321 & 0.308 & & 0.353 & 0.31 & \\
\hline $\begin{array}{l}\text { Household income per } \\
\text { capita (ln) } \\
\text { Having medical }\end{array}$ & 0.037 & 0.022 & & 0.028 & 0.023 & & -0.069 & 0.045 & & -0.078 & 0.046 & + \\
\hline insurance & & & & 0.299 & 0.159 & + & & & & -0.071 & 0.336 & \\
\hline Physical examination & & & & 0.609 & 0.063 & $* * *$ & & & & 0.39 & 0.116 & $* *$ \\
\hline Random effect & 0.361 & 0.054 & $*$ & 0.37 & 0.057 & $* * *$ & 0.248 & 0.105 & $*$ & 0.239 & 0.105 & $*$ \\
\hline
\end{tabular}

Note: $1{ }^{* * *} \mathrm{P}<0.001 ;{ }^{* *} \mathrm{P}<0.01 ;{ }^{*} \mathrm{P}<0.05 ;+\mathrm{P}<0.1$;

2. Coefficients are adjusted by age, gender and marital status in all models.

Our study also finds that socioeconomic conditions were strongly and positively associated with the awareness and treatment rates of hypertension. This evidence was based on a large national representative samples with more than 6,800 people with hypertension. The middle-aged and elderly living in the urban area, people who live in the more developed eastern China and working in government or institutions or retired had higher rates of awareness and treatment of hypertension. Advantages of awareness and treatment of hypertension in elderly with higher socioeconomic status will help reduce their disadvantages on the prevalence of hypertension. This may suggest that China is in transition and as the economic conditions continue developing, the hypertension will be reduced in those with a higher level of SES.

In addition, having medical insurance and taking physical examination regularly may contribute to the positive association of SES with the awareness and treatment rates. As the proportion of awareness and treatment of hypertension are quite low in China, more medical resources and policies are needed to prevent from and control for hypertension, especially in the groups with lower socio- economic status. We also found a significant random-effect, suggesting that factors at the community may help to reduce the disparity of awareness and treatment of hypertension. However, a study in Japan did not find a clear association of SES with unaware, untreated and uncontrolled hypertension (18), although a multi-nation study in urban clinics of 12 countries in Sub-Saharan Africa also indicated that people in the lowest individual wealth groups are more likely to have uncontrolled hypertension (14).

\section{CONFLICTS OF INTEREST}

We declare that there is no conflict of interest regarding the publication of this paper.

\section{ACKNOWLEDGEMENTS}

This study is supported by National Natural Science Foundations of China (Grant No. 71490732).

\section{REFERENCES}


1. Egan BM, Kjeldsen SE, Grassi G, Esler M, Mancia G. The global burden of hypertension exceeds 1.4 billion people: should a systolic blood pressure target below 130 become the universal standard? J Hypertens. 2019.

2. China NHCotPsRo. China Health and Family Planning Statistics Yearbook 2017. Beijing: : Peking Union Medical College Press; 2018.

3. Cockerham WC. Health lifestyle theory and the convergence of agency and structure. J Health Soc Behav. 2005;46(1):5167.

4. Winkleby MA, Jatulis DE, Frank E, Fortmann SP. Socioeconomic status and health: how education, income, and occupation contribute to risk factors for cardiovascular disease. Am J Public Health. 1992;82(6):816-20.

5. Marmot M. Social determinants of health inequalities. Lancet. 2005;365(9464):1099-104.

6. Cummins S, Stafford M, Macintyre S, Marmot M, Ellaway A. Neighbourhood environment and its association with self rated health: evidence from Scotland and England. J Epidemiol Community Health. 2005;59(3):207-13.

7. Leng B, Jin Y, Li G, Chen L, Jin N. Socioeconomic status and hypertension: a meta-analysis. J Hypertens. 2015;33(2):2219.

8. Wee LE, Koh GC. Individual and neighborhood social factors of hypertension management in a low-socioeconomic status population: a community-based case-control study in Singapore. Hypertens Res. 2012;35(3):295-303.

9. Leigh JP, Du J. Are low wages risk factors for hypertension? Eur J Public Health. 2012;22(6):854-9.

10. Kaczmarek M, Stawinska-Witoszynska B, Krzyzaniak A, Krzywinska-Wiewiorowska M, Siwinska A. Who is at higher risk of hypertension? Socioeconomic status differences in blood pressure among Polish adolescents: a populationbased ADOPOLNOR study. Eur J Pediatr. 2015;174(11):1461-
73.

11. Fernald LC, Adler NE. Blood pressure and socioeconomic status in low-income women in Mexico: a reverse gradient? J Epidemiol Community Health. 2008;62(5):e8.

12. Cois A, Ehrlich R. Analysing the socioeconomic determinants of hypertension in South Africa: a structural equation modelling approach. BMC Public Health. 2014;14:414.

13. Ma YX, Zhang B, Jiang WB, Wang HJ, Du WW, Su C, et al. [The impact of socioeconomic status on the prevalence of hypertension among adults in 9 provinces of China, 19912009]. Zhonghua Liu Xing Bing Xue Za Zhi. 2013;34 (11):1051-4.

14. Antignac M, Diop IB, Macquart de Terline D, Kramoh KE, Balde DM, Dzudie A, et al. Socioeconomic Status and Hypertension Control in Sub-Saharan Africa: The Multi-nation EIGHT Study (Evaluation of Hypertension in Sub-Saharan Africa). Hypertension. 2018;71(4):577-84.

15. Zhao Y, Hu Y, Smith JP, Strauss J, Yang G. Cohort profile: the China Health and Retirement Longitudinal Study (CHARLS). Int J Epidemiol. 2014;43(1):61-8.

16. Grotto I, Huerta M, Sharabi Y. Hypertension and socioeconomic status. Curr Opin Cardiol. 2008;23(4):335-9.

17. Schumann B, Seidler A, Kluttig A, Werdan K, Haerting J, Greiser KH. Association of occupation with prevalent hypertension in an elderly East German population: an exploratory cross-sectional analysis. Int Arch Occup Environ Health. 2011;84(4):361-9.

18. Satoh A, Arima H, Ohkubo T, Nishi N, Okuda N, Ae R, et al. Associations of socioeconomic status with prevalence, awareness, treatment, and control of hypertension in a general Japanese population: NIPPON DATA2010. J Hypertens. 2017;35(2):401-8.

How to cite this article:

Xia C, Li J. Socioeconomic Status Impact Hypertensive Risk and Treatment among Older Adults in China. Glob Clin Transl Res. 2019; 1 (2): 62-68. 